\title{
Karsha Drawdown Explorer Demonstration
}

\author{
Tharindu Peiris \\ Lanka Software Foundation \\ tharindup@opensource.lk
}

\author{
Joe Langsam \\ U. Maryland \\ joe@langsam.org
}

\author{
Louiqa Raschid \\ U. Maryland \\ louiqa@umiacs.umd.edu
}

\begin{abstract}
This is a demonstration paper of the Karsha Explorer to visualize price changes in the S\&P 500 Index dataset.

\section{Keywords}

Monthly drawdowns; market capitalization; visual analytics.

\section{INTRODUCTION}

An overarching goal of systemic risk research is to identify predictors of incipient market instability. We seek to identify extreme price change episodes of individual equities as a possible signal, together with changes in market volume, volatility, etc. Empirical patterns around significant price changes of equities have been studied widely. An overview is presented in Sornette, 2014. In this demonstration paper, we describe a novel Explorer tool to visualize monthly price variations for equities in the S\&P 500 Index. The user can filter the monthly data to highlight equities that experience significant variations. The tool will allow the user to compare signals from individual equities that have experienced significant variations with the contemporaneous moves in the S\&P 500 index for that month. These combinations of extreme moves in individual equities and the market are the basis to create a pattern template of five patterns. We use the value of (most) significant losses of market capitalization of the individual equities, as well as the end-of-month return of the index, to label each month with one of the five patterns.
\end{abstract}

\section{DRAWDOWN DATASET}

We consider the individual equities that comprise the S\&P 500 Index; we use the period 2004-2014 for the demonstration. Since individual firms do not exist in isolation, their equity returns share significant common statistical components with the broader market. This is emphasized by equilibrium models such as the capital asset pricing model (CAPM). For an overview of equilibrium approaches to financial asset prices, see Duffie, 2001 and Cochrane, 2005. The monthly drawdown for each equity is computed as its maximal cumulative decrease in market

Permission to make digital or hard copies of all or part of this work for personal or classroom use is granted without fee provided that copies are not made or distributed for profit or commercial advantage and that copies bear this notice and the full citation on the first page. Copyrights for components of this work owned by others than ACM must be honored. Abstracting with credit is permitted. To copy otherwise, or republish, to post on servers or to redistribute to lists, requires prior specific permission and/or a fee. Request permissions from permissions@acm.org. DSMM' 16, June 26-July 01 2016, San Francisco, CA, USA (C) 2016 ACM. ISBN 978-1-4503-4407-4/16/06 ..\$15.00 DOI: http://dx.doi.org/10.1145/2951894.2951899 capitalization, based on the CAPM-adjusted return residuals during the month. All changes are measured relative to the equity price at the start of the month. This creates a regularly spaced monthly time series. Figure 1 illustrates how the Karsha Explorer provides a chart (Market Capitalization versus Time) to explore the most significant drawdowns in each time period.

\section{PATTERNS}

We define a pattern template based on the following features as illustrated in Figure 2: [Note that all bars are in the positive direction but a loss should be aligned in the negative direction.]

Orange bar: This represents the lowest return value of the S\&P 500 Index for each month.

Blue bar: This represents the cumulative loss of market capitalization over the Top $\mathrm{K} \%$ equities with a significant CAPM drawdown. This is accumulated for the corresponding Index Interval, i.e., between the lowest return value of the S\&P 500 Index in month M-1 and in month $\mathrm{M}$. We note that in some small number of cases the blue bar is actually a gain.

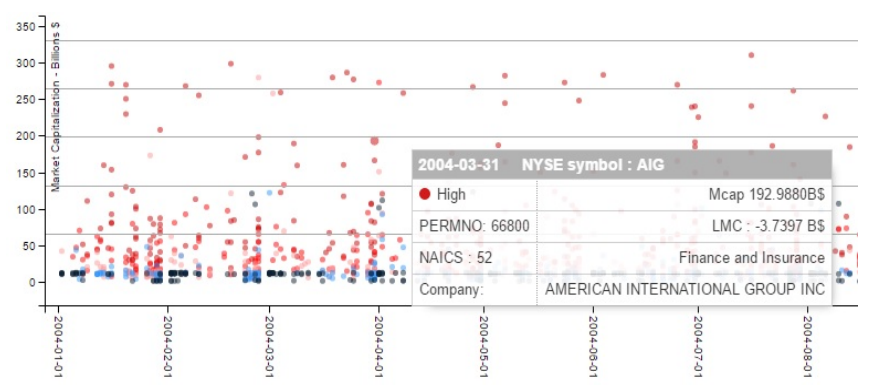

Figure 1: Layout of the most significant CAPM drawdowns for the individual equity for that month. Selecting each data point will show a dialog box with the name of the equity, the NYSE symbol, the NAICS code associated with that equity and the current level of market capitalization as well as the loss of market capitalization.

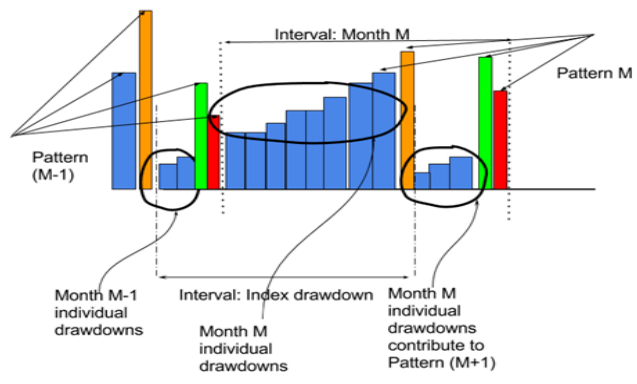

Figure 2: Features within the Index and Monthly Interval 
Red bar: The represents the end_of_month return (loss or gain of market capitalization) for the Blue bar set of equities.

Green bar: This represents the end_of_month return (loss or gain of market capitalization) for the $\mathrm{S} \& \overline{\mathrm{P}} 500$ Index.

We consider combinations of Low / High values, as well as Negative / Positive values, for these bars, to identify the following five patterns, as illustrated in Figure 3. We note that these five patterns were primarily chosen since the specific combinations of values appeared frequently in the data. There may be additional combinations that did not stand out in the data or were not meaningful, e.g., the value of the Red bar is constrained by the maximum value of the Blue bar, as will be discussed.

PUSHDOWN: The Blue bar shows a LARGE NEGATIVE value. The Red bar remains negative and the Green bar has a LARGE NEGATIVE value. To explain, the initial large loss of market capitalization of the Blue bar equities did not recover and this "pushed down" the value of the S\&P 500 index.

LOSS NO IMPACT: The Blue bar shows a LARGE NEGATIVE value. However, the Red bar is a small negative or even a small positive value. The Green bar is close to zero or a small positive value. To explain, the loss of market capitalization of the Blue had no impact on the value of the S\&P 500 index.

NO IMPACT: The values for the Blue, Red and Green bar are very small. This is a month without much change in individual equities or in the S\&P 500 index.

LOW LOSS HIGH GAIN (LLHG): The Blue shows a small negative value. The Green bar shows a LARGE POSITIVE value. This is a month where few individual equities show a loss and where there is a gain in the S\&P 500 index.

NON ALIGN: The Blue bar shows a LARGE NEGATIVE value. However, the Green bar shows a LARGE POSITIVE value. To explain, the initial large loss of market capitalization of some equities is offset by a strong return, possibly from these or other equities, such that the S\&P 500 shows a gain.

Figure 4 shows the chosen label for each month in the period 2004-2014. We note that the range for Low/High market capitalization was computed both locally, i.e., based on the range of values for that year, or globally, based on the range of values for the 10 year period 2004-2014.

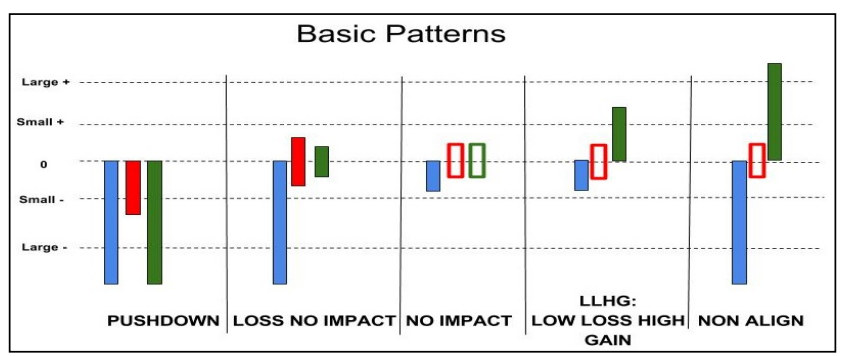

Figure 3: Five Patterns in the Template.

\section{ONGOING WORK}

We first consider some current limitations of the somewhat artificial monthly interval to compute drawdowns. In Figure 5, the PUSHDOWN pattern continues over from one month to the next (October and November 2008). In Figure 6, a PUSHDOWN in February 2009, where the Index drawdown occurs at the end of the month, is followed by an LLHG pattern in March 2009. We are extending our approach to consider SIGNIFICANT LOCAL minima and maxima that are not constrained by monthly intervals.
We will also include turnover, e.g., market volume, in defining patterns. The patterns will also be connected to economic hypotheses of market behavior, e.g., flight to safety.

\begin{tabular}{|c|c|c|c|c|}
\hline [ LNImpct] & [ LNImpct] ] & [ LNImpct] & [None] & [None] \\
\hline [Nolmpct] & [NonAlign] & [NonAlign] & [LNImpct] & [None] \\
\hline [ LWImpet] & [NonAlign ] & [LNImpct] & [Pshdown] & [LNImpet] \\
\hline [LHG] & [NonAlign] & [NonAlign ] & [ LNImpct] ] & [LLHG] \\
\hline [NonAlign] & [LNImpct] & [Pshdown] & [Pshdown] & [LHG] \\
\hline [LNImpct] & [NonAlign] & [ LNImpct] & [None] & [ LNImpct] ] \\
\hline
\end{tabular}

Figure 4. Pattern occurrences

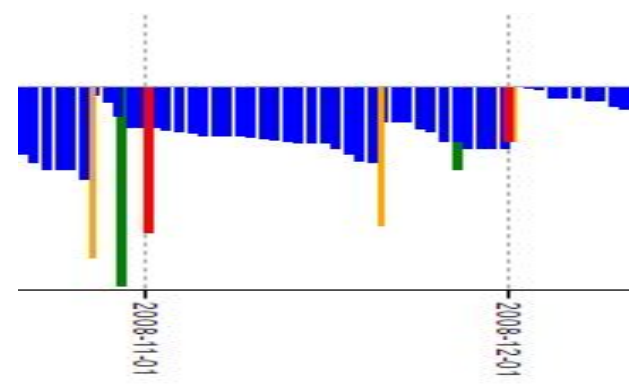

Figure 5: PUSHDOWN followed by PUSHDOWN

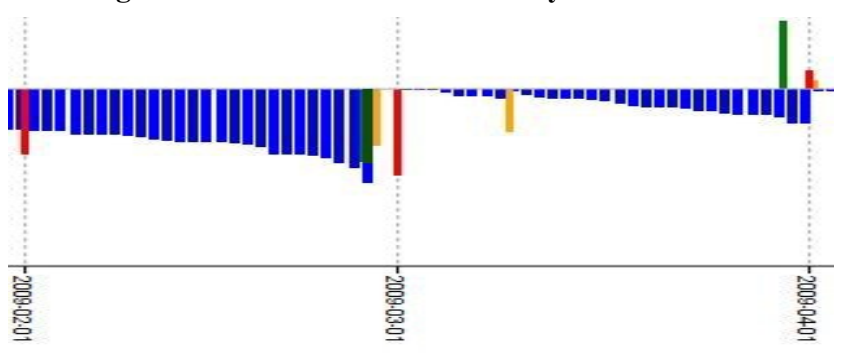

Figure 6: PUSHDOWN followed by LLHG

\section{ACKNOWLEDGMENTS}

The Karsha Explorer was funded by the National Institutes of Standards and Technology grant 70NANB15H194, the National Science Foundation grant CNS 1305368 and the Lanka Software Foundation. We thank Mark Flood and Kevin Sheppard for their significant research contributions.

\section{REFERENCES}

[1] Wharton Research Data Services [online] Available : https://wrds-web.wharton.upenn.edu/wrds/

[2] Karsha - Drawdown website http://karsha.umiacs.umd.edu/

[3] Sornette, Didier, Why Stock Markets Crash: Critical Events in Complex Financial Systems. Princeton, N.J. ; Oxford: Princeton University Press, 2003.

[4] Cochrane, John H, Asset Pricing. Rev. ed. Princeton, N.J.; Oxford: Princeton University Press, 2005.

[5] Duffie, Darrell. Dynamic Asset Pricing Theory. 3rd ed. Princeton, N.J.; Oxford: Princeton University Press, 2001. 